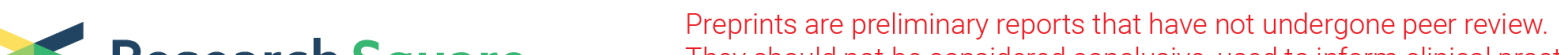 $\begin{array}{ll}\text { Research Square } & \text { They should not be considered conclusive, used to inform clinical practice, } \\ \text { or referenced by the media as validated information. }\end{array}$
}

\section{Effect of Yangyin Shuxin Decoction on Exercise Capacity in Patients with Heart Failure with Normal Ejection Fraction: Rationale and Design of a Randomized Controlled Trial}

\section{Zhiqiang Zhao}

First Teaching Hospital of Tianjin University of Traditional Chinese Medicine

\section{Xianliang Wang}

First Teaching Hospital of Tianjin University of Traditional Chinese Medicine

\section{Shuai Wang}

First Teaching Hospital of Tianjin University of Traditional Chinese Medicine

\section{Ruijuan Zhou}

First Teaching Hospital of Tianjin University of Traditional Chinese Medicine

\section{Quan Su}

First Teaching Hospital of Tianjin University of Traditional Chinese Medicine

Yu Liu

First Teaching Hospital of Tianjin University of Traditional Chinese Medicine

Qing Li

First Teaching Hospital of Tianjin University of Traditional Chinese Medicine

Shanshan Lin

First Teaching Hospital of Tianjin University of Traditional Chinese Medicine

Hua Liu

First Teaching Hospital of Tianjin University of Traditional Chinese Medicine

Jingyuan Mao ( $\nabla$ jymao@126.com )

First Teaching Hospital of Tianjin University of Traditional Chinese Medicine

https://orcid.org/0000-0002-9882-7406

\section{Study protocol}

Keywords: heart failure, Yangyin Shuxin Decoction, traditional Chinese medicine, randomized controlled trial

Posted Date: February 12th, 2020

DOl: https://doi.org/10.21203/rs.2.23369/v1

License: @ (i) This work is licensed under a Creative Commons Attribution 4.0 International License. Read Full License 


\section{Abstract}

Background The incidence of heart failure with normal ejection fraction (HFNEF) is increasing yearly, accounting for approximately half of all heart failure cases. Even after standardized treatment, the patient's prognosis is not good. Therefore, it is necessary to explore new treatment methods for HFNEF. Yangyin Shuxin Decoction, a traditional Chinese medicine prescription from our clinical experience in the treatment of HFNEF, has a potential cardioprotective effect. Preliminary clinical trials have shown that this prescription can improve the quality of life of HFNEF. This prompted us to use more objective indicators to further evaluate whether Yangyin Shuxin Decoction can improve the exercise capacity in HENEF patients.

Methods This is a single-center parallel randomized controlled trial. The 64 patients who met the inclusion criteria were from the Cardiovascular Clinic. They will be randomly assigned to the treatment group (Yangying Shuxin Decoction combined with standard treatment) or the control group (standard treatment) according to the ratio of 1:1. The course of treatment will be 2 weeks. Both groups were interviewed at the following time points: of at enrollment (V1), and week 2 (V2), week 4 (V3), week 8 (V4), and week 12 (V5) after enrollment. The primary indicator is the peak oxygen consumption(Peak VO2) of the cardiopulmonary exercise test (CPET). Secondary indicators include CPET indicators such as anaerobic threshold oxygen consumption, carbon dioxide ventilation equivalent slope, echocardiographic indicators such as the ratio of mitral peak velocity of early filling to early diastolic mitral annular velocity(E/e'), left atrial volume index (LAVI), left ventricular mass index (LVMI), the peak velocity of tricuspid regurgitation (TR), B-type natriuretic peptide (BNP), New York Heart Association (NYHA) cardiac function grading, and so on. These indicators will be used to evaluate the effect of Yangyin Shuxin Decoction on exercise capacity in patients with HFNEF.

Discussion At present, it is unclear whether the exercise capacity can be maintained after long-term use of Yangyin Shuxin Decoction. In this study, we will evaluate whether Yangyin Shuxin Decoction can improve the exercise capacity and quality of life of patients with HFNEF. This will provide an objective basis for the therapeutic effect of traditional Chinese medicine on HFNEF.

\section{Background}

China gradually enters an aging society and the incidence of heart failure with normal ejection fraction (HFNEF) is increasing yearly. ${ }^{1}$ These patients account for approximately half of all patients with heart failure (HF). ${ }^{2-4}$ Betaadrenergic receptor blockers, angiotensin-converting enzyme inhibitors (ACEI), angiotensin receptor blockers (ARB), and so on are routinely used to treat HFNEF. However, they have not improved the prognosis and reduced the mortality of patients with HFNEF. ${ }^{5-7}$ Patients with HFNEF who received conventional treatment still have problems, such as low exercise capacity and low quality of life. ${ }^{8}$ Previous clinical studies ${ }^{9-12}$ suggested that traditional Chinese medicine (TCM) had certain efficacy in relieving symptoms, increasing activity capacity, improving quality of life, and other aspects in patients with HFNEF. However, the quality of these studies is poor. Some deficiencies reduce the level of evidence such as large differences in the study population, unclear inclusion/exclusion criteria, non-uniform TCM syndromes, relatively single clinical evaluation indicators, and other problems. ${ }^{13}$

Yangyin Shuxin Decoction is a TCM prescription for treating HFNEF. It has the effects of nourishing Yin (Yangyin), promoting blood circulation (Huoxue), and clearing away heat (Qingre). Preliminary clinical trials have proved that it can improve the quality of life of patients with HFNEF. ${ }^{14}$ The single drug component of each drug in the prescription has multiple targets to improve the heart and lung functions and increase the exercise capacity. Hence, we planned to use more objective indicators to further evaluate whether Yinyin Shuxin can improve the exercise capacity of patients with HFNEF. 
We hypothesized that Yangyin Shuxin Decoction could improve the exercise capacity of patients with HFNEF. Moreover, we designed this randomized controlled trial to compare the efficacy of conventional western medicine and Yangyin Shuxin Decoction combined with conventional western medicine on exercise capacity in patients with HFNEF. The relevant design principles and implementation schemes of the randomized controlled trial protocol are as follows.

Figure 1

\section{Methods}

\section{Study design}

This is a single-center, prospective, parallel, randomized controlled trial. Based on a computergenerated randomized number, 64 patients with HFNEF will be randomly assigned to either the treatment or control group. Patients in the treatment and control groups will be treated with a drug intervention for 2 weeks and followed up for 12 weeks. We will terminate this test when the following situations occur: 1) a serious safety incident occurred during the test; 2) there are major errors in the clinical trial protocol; 3) serious deviations occur so that it is difficult to evaluate the efficacy of the drug; and 4) the project management department cancels the test. A data monitoring committee will be established, mainly to make interim analysis and assess adverse events. The committee will review the core trial processes and documents, and discuss any amendments to the main study protocol. Any adverse event will be recorded in the CRF and reported to the data monitoring committee in a timely manner. We will provide appropriate compensation for any injured subjects. The Standard Protocol Items: Recommendations for Interventional Trials (SPIRIT) checklist is provided as Additional file 1.

\section{Participants}

All of the 64 patients with HFNEF will be enrolled in the Department of Cardiology, the First Teaching Hospital of Tianjin University of TCM. First, the patients will be fully introduced to the benefits and risks of the treatment. Second, the patients need to sign the informed consent on a voluntary basis. Then, the patients will be divided into the treatment (Yangying Shuxin Decoction combined with the standard treatment) or control (standard treatment) groups according to the coding sequence from the pre-set random number table. The inclusion and exclusion criteria are shown in Table 1.

\section{Table 1. Eligibility criteria}




\section{A. Inclusion criteria}

1. Age $>40$ years;

2. Patients with the following symptoms and/or signs:

1₫Symptoms: shortness of breath or weakness or reduced exercise endurance or dyspnea at night or orthopnoea;

2₫Signs: jugular hypertension, hepatojugular reflux, galloping rhythm, cardiac hypertrophy, weight gain, peripheral edema, or pulmonary rales

\section{3. $\mathrm{LVEF} \geq 50 \%$}

4. $\mathrm{BNP}>35 \mathrm{pg} / \mathrm{mL} \square$

5. Meet at least one of the following criteria:

1ロThere are cardiac structural changes: left atrial enlargement (LAVI>34 ml/ $\mathrm{m}^{2}$ ) or left ventricular hypertrophy (LVMI: male $>115 \mathrm{~g} / \mathrm{m}^{2}$, female>95 $\mathrm{g} / \mathrm{m}^{2}$ );

2₫Diastolic dysfunction: $\mathrm{E} / \mathrm{e}^{\prime} \geq 13$ and $\mathrm{e}^{\prime} \square 9 \mathrm{~cm} / \mathrm{s}$;

6. Sign the informed consent

\section{B. Exclusion criteria}

1. Acute coronary syndrome, congenital heart disease, severe valvular disease, constrictive pericarditis, hypertrophic cardiomyocyte, and restrictive cardiomyopathy;

2. Patients with history of intracoronary stent implantation, permanent pacemaker, implantable defibrillator (ICD), or left ventricular assist device implantation or coronary artery bypass grafting within nearly 90 days;

3. Systolic pressure $>160 \mathrm{mmHg}$ or $<90 \mathrm{mmHg}$ at intake;

4. Chronic lung disease requiring oxygen therapy or drug intervention;

5. Cerebral infarction within 90 days;

6. Special treatments should be used for patients with comorbidities such as severe liver or renal failure and malignant tumor, which could influence the clinical treatment of HFNEF;

7. Pregnant or breastfeeding women, or women at childbearing age without reliable methods of contraception;

8. Unable to complete cardiorespiratory exercise test;

9. Poor patient compliance;

10. Participated in other studies within 2 months 
The follow-up period was 12 weeks. A full physical examination and assessment of adverse events will be performed for all participants. After the patient signs the informed consent form, we will collect general information including demographics, medical history, and concomitant medications. Two clinical controls were performed at the time of enrollment (V1) and week 2 (V2). Indicators include cardiac ultrasound, CPET, BNP, NYHA cardiac function grading, EQ-5D-5L, TCM four-diagnostic information score, syndrome judgment, blood pressure, heart rate, weight, and so on. Blood and urine samples will also be taken. During the follow-up period, the investigator will contact the participants via telephone at weeks 4 (V3), 8 (V4), and 12 (V5) to monitor the patient's blood pressure, weight, NYHA cardiac function, hospitalization/outpatient costs, and compound endpoint events to assess the patients' quality of life. This program was prepared in accordance with the standard protocol project SPIRIT 13. The specific process of the study is shown in Table 2.

\section{Table 2. Research access flow chart}




\begin{tabular}{|c|c|c|c|c|c|}
\hline Study phase & Screening/enrolment & & Follc & w-up & \\
\hline Time & Baseline & Week 2 & Week 4 & Week 8 & Week 12 \\
\hline Visit & V1 & V2 & V3 & V4 & V5 \\
\hline Confirm eligibility & Ö & & & & \\
\hline Written informed consent & Ö & & & & \\
\hline Data collection & & & & & \\
\hline General data & Ö & & & & \\
\hline Medical history & Ö & & & & \\
\hline Physical examination & Ö & Ö & & & \\
\hline Current medications & Ö & Ö & & & \\
\hline Dispense drugs & Ö & & & & \\
\hline Record drug recall & & Ö & & & \\
\hline Compliance judgment & & Ö & & & \\
\hline Observation of efficacy & & & & & \\
\hline CPET & Ö & Ö & & & \\
\hline Echocardiography & Ö & Ö & & & \\
\hline NYHA classification & Ö & Ö & Ö & Ö & Ö \\
\hline EQ-5D-5L & Ö & Ö & & & \\
\hline TCM 4 diagnostic information & Ö & Ö & & & \\
\hline Chinese medical syndrome elements & Ö & Ö & & & \\
\hline BNP, BUA & Ö & Ö & & & \\
\hline UAlb, Cr, UAlb/Cr & Ö & Ö & & & \\
\hline Endpoint event & & Ö & Ö & Ö & Ö \\
\hline Hospitalization/outpatient costs & & & Ö & Ö & Ö \\
\hline Safety observation & Ö & Ö & Ö & Ö & Ö \\
\hline Blood pressure, heart rate, weight & Ö & Ö & Ö & Ö & Ö \\
\hline Blood tests & Ö & Ö & & & \\
\hline CR, BUN, ALT & Ö & Ö & & & \\
\hline Electrolyte & Ö & Ö & & & \\
\hline Adverse events & Ö & Ö & Ö & Ö & Ö \\
\hline Study completion status & & & & & Ö \\
\hline
\end{tabular}


Note: BUA: blood uric acid; UAlb: urine microalbumin; CRF: case report form.

\section{Interventions}

Other TCM preparations are not allowed during the washout period for two weeks. The patients in the treatment group will be treated with conventional western medicine combined with Yangyin Shuxin Decoction $150 \mathrm{ml}$, twice a day. All Chinese herbal medicines in Yangyin Shuxin Decoction are from the Department of Pharmacy, the First Teaching Hospital of Tianjin University of TCM. The decocting room is uniformly fried and made into a vacuum package of $150 \mathrm{ml}$. The remaining decoction will be recycled if the participants withdraw from the test midway. The patients in the control group will receive conventional western medicine treatment. The duration will be 2 weeks. Both groups will be interviewed at the following time points: enrollment (V1), week 2 (V2), week 4 (V3), week 8 (V4), and week 12 (V5) after enrollment.

The TCM theory believes that patients with HFNEF have clinical syndrome characteristics of yin deficiency, blood stasis, and internal heat. ${ }^{15}$ Each of the single-drug ingredients in Yangyin Shuxin Decoction includes a variety of compounds such as polyphenols, terpenoids, saponins, and alkaloids that are beneficial to the cardiovascular system. The relevant bioactive ingredients and potential mechanisms are shown in Table 3. These ingredients have the combined effects of improving heart and lung functions, increasing activity tolerance, improving microcirculation, and improving immunity and body antioxidants in patients with HFNEF.

Western medicine standard treatment plan is implemented according to the "China Heart Failure Diagnosis and Treatment Guide 2014"16 and "2016 ESC Guidelines for the diagnosis and treatment of acute and chronic heart failure"17. The Western medicine standard treatment includes health education for patients to help them establish a heart-healthy lifestyle (such as salt restriction, water restriction, weight monitoring, physical exercise, smoking cessation, alcohol withdrawal, and so om) and medication guidance and emergency management instructions. In addition, other TCMs for the treatment of cardiovascular diseases should be avoided.

Table 3. Cardiovascular effects and potential mechanisms of active ingredients 


\begin{tabular}{|c|c|c|c|c|}
\hline Herbs & Bioactive ingredients & Beneficial effects & $\begin{array}{c}\text { Potential } \\
\text { mechanisms }\end{array}$ & Ref.\# \\
\hline Fructus corni & $\begin{array}{c}\text { Cornus } \\
\text { officinalis saponins }\end{array}$ & $\begin{array}{l}\text { Anti-inflammatory; } \\
\text { protecting the } \\
\text { cardiovascular and } \\
\text { cerebrovascular } \\
\text { system; } \\
\text { inhibiting myocardial } \\
\text { cell apoptosis; reverse } \\
\text { cardiac hypertrophy }\end{array}$ & $\begin{array}{l}\text { Decreasing the } \\
\text { activity of serum } \\
\text { CPK and LDH口 } \\
\text { decreasing the } \\
\text { expression of } \\
\text { P47phox and } \\
\text { Nox4 in the } \\
\text { myocardium }\end{array}$ & 18,19 \\
\hline $\begin{array}{c}\text { Radix } \\
\text { Ophiopogonis }\end{array}$ & $\begin{array}{c}\text { Total saponins of } \\
\text { Ophiopogon; } \\
\text { Polysaccharide MDG- } \\
1 \text { from Ophiopogon } \\
\text { japonicas; } \\
\text { Ophiopogon D }\end{array}$ & $\begin{array}{c}\text { Promoting myocardial } \\
\text { injury, healing and } \\
\text { narrowing the } \\
\text { infarction and } \\
\text { necrotic areas }\end{array}$ & $\begin{array}{c}\text { Reducing } \\
\text { malondialdehyde } \\
\text { and free fatty } \\
\text { acids; effects on } \\
\text { the pituitary } \\
\text { adrenocortical } \\
\text { system }\end{array}$ & 20,21 \\
\hline Rhizoma Polygonatum & $\begin{array}{c}\text { PP; } \\
\text { EE of Rhizoma } \\
\text { Polygonatum }\end{array}$ & $\begin{array}{l}\text { Inhibiting myocardial } \\
\text { cell apoptosis; } \\
\text { enzyme inhibition, } \\
\text { anti-inflammation, } \\
\text { anti-oxidation }\end{array}$ & $\begin{array}{c}\text { Inhibiting the } \\
\text { release of various } \\
\text { enzymes; } \\
\text { increasing SOD } \\
\text { activity and } \\
\text { decreasing MDA } \\
\text { content }\end{array}$ & 22 \\
\hline Coptidis rhizoma & $\begin{array}{l}\text { Alkaloids; } \\
\text { berberine }\end{array}$ & $\begin{array}{l}\text { Positive inotropic } \\
\qquad \text { action; } \\
\text { vasodilatation; heart } \\
\text { cell protection; } \\
\text { antiapoptotic }\end{array}$ & $\begin{array}{c}\text { Blocking K+ } \\
\text { channels; } \\
\text { activating AMP } \\
\text { protein activated } \\
\text { protein kinase } \\
\text { and P13K/Akt } \\
\text { pathways }\end{array}$ & 23,24 \\
\hline Carapax trionycis & Trionyx sinensis & $\begin{array}{l}\text { Resistance to hypoxia; } \\
8 / 18\end{array}$ & Increasing the & \\
\hline
\end{tabular}


polysaccharides;

Trionyx sinensis extract

(TSWE)

Radix Salviae

miltiorrhizae

Lumbricus

Rhizoma pinelliae
Terpenoids

Tanshinones

Unsaturated fatty acid

Vaccenic acid

arachidonic acid

Platelet-like activating

factor

Lumbricus peptides

Alkaloids
Organic acids
Volatile oils
ß-stanols

improving immune

activity of $\mathrm{LDH}$

25

function
26,27 calcineurin/NFAT pathway; antioxidant; anti- antiapoptosis inflammatory; antithrombotic Thrombolysis and anticoagulation;

Antihypertensive; regulation of the immune Reducing platelet 28 adhesion and prolonging thrombosis;

$$
\begin{gathered}
\text { Inhibiting ACE } \\
\text { activity }
\end{gathered}
$$
Anti-arrhythmia;
increase coronary
flow;

protecting the heart ischemia reperfusion injury and vascular Decreasing the 29-31 activity of serum lactate dehydrogenase and phosphocreatine endothelial cell injury 


\begin{tabular}{|c|c|c|c|c|}
\hline & & & $\begin{array}{l}\text { tumor necrosis } \\
\text { factor-alpha }\end{array}$ & \\
\hline \multirow[t]{7}{*}{ Trichosanthes peel } & & Anti-myocardial & Enhancing free & 32 \\
\hline & amino acids & ischemia; & radical & \\
\hline & flavonoids & anti-atherosclerosis; & $\begin{array}{c}\text { scavenging } \\
\text { ability; }\end{array}$ & \\
\hline & & protecting vascular & decreasing INOS & \\
\hline & & endothelium; & activity and NO & \\
\hline & & dilating blood vessels; & synthesis and free & \\
\hline & & resistance to hypoxia & radical formation & \\
\hline \multirow[t]{8}{*}{ Fructus Aurantii } & Alkaloid synephrine & Raising blood & Promoting- & 33 \\
\hline & $\pi$ & pressure; & adrenalin & \\
\hline & $1 \mathrm{~s}-$ & & secretion & \\
\hline & mennуıугаmmena vonoias & anu-aneroscierosis; & indirectly; & \\
\hline & hesperidin & inhibiting thrombosis & maintaining & \\
\hline & Nobisexualletin & & osmotic pressure; & \\
\hline & & & inhibiting & \\
\hline & & & vascular sclerosis & \\
\hline
\end{tabular}

Note: CPK: creatine phosphokinase; LDH: lactate dehydrogenase; PP: polygonatum polysaccharide; EE: ethanol extract; SOD: superoxide dismutase; MDA: malondialdehyde; AMP: adenosine monophosphate; $\mathrm{K}^{+}$: calcium ion; P13K: phosphatidylinositol 3-kinase.

\section{Outcomes}

Primary outcome: the change of Peak VO2 in cardiopulmonary exercise test .

\section{Secondary outcomes:}

\anaerobic threshold and ventilatory equivalent for carbon dioxide (VE/VCO2) slope detected in the cardiopulmonary exercise test.

口E/e', LAVI, LVMI, and TR detected with ultrasonic cardiogram. 
口BNP, NYHA cardiac function grading, EQ-5D-5L, TCM four-diagnostic information score, syndrome judgment, compound endpoint events, and so on.

Security outcomes: Vital signs, some laboratory tests, and adverse events are considered as safety outcomes. Vital signs, including blood pressure and heart rate, routine laboratory tests (routine urinalysis, routine blood test, and hepatic and renal functions), and electrocardiograms, and the adverse events will be documented at each visit.

\section{Patient and public involvement}

The patients or the public were not involved in the design or in conducting, reporting, or disseminating our research.

\section{Sample size}

The sample size is computed based on the literature "Effect of If-channel inhibition on hemodynamic status and exercise capacity in heart failure with preserved ejection fraction: a randomized trial”, 34 peak VO2 on day 7 is $3.0 \pm 3.6 \mathrm{ml} / \mathrm{kg} / \mathrm{min}$ in the treatment group and $0.4 \pm 2.7 \mathrm{ml} / \mathrm{kg} / \mathrm{min}$ in the control group. Sixty-four patients will be recruited with a single-sided alpha of 0.05 , a power (1- $\beta$ ) of 0.90 , and a dropout rate of $20 \%$. The calculation formula is as follows ${ }^{35}$ :

[See supplementary files for formula.]

\section{Blinding}

Blinding the researchers responsible for the implementation and patients included is not possible due to the particularity of dosage forms. The investigators are responsible for distributing the drugs. To ensure the reliability of the test, the personnel and statistical experts performing the outcome index evaluation will be blinded. All research team members were instructed not to communicate with the participants regarding their allocation.

\section{Data collection and management}

To assess the patients' health status since the last visit and HFNEF-related re-hospitalization or unplanned medical conditions throughout the study period, the two groups will be contacted every 2 weeks or a month. All original data will be observed directly by clinical researchers and documented completely and timely in the case report form (CRF), including the reasons why patients cannot participate. To ensure the reliability of data, the CRF will be entered by the double-entry method. All 
errors will be crossed out and corrected and signed by the corresponding investigator. All these data will be locked in a separate cabinet. Only authorized investigators are permitted to access this information.

\section{Statistical analysis}

SPSS23.0 statistical analysis software will be used to calculate the test data, and descriptive statistics will be conducted for all the data. For the differences between the test groups, chi-square test will be used for the counting data. The t-test will be applied when normality (and homogeneity of variance assumptions) is satisfied, otherwise the rank sum test will be used.

The number of screened patients and reasons for exclusion will be reported, as well as protocol violations and reasons. An effectiveness analysis will be conducted using the randomized populations. Participants who have received treatment but there is no valid evaluation data will be considered as missing and will be included in the effectiveness analysis.

\section{Discussion}

To the best of our knowledge, this is the first randomized controlled trial using cardiopulmonary exercise test indexes to evaluate the impact of TCM on the exercise capacity of patients with HFNEF. Cardiopulmonary exercise test indicators (including peak VO2, anaerobic threshold, VE/VCO2 slope, and so on) are taken as the main indicators, and combined with echocardiography, BNP, NYHA cardiac function grading, generic EQ-5D-5L, and other indicators normally used to evaluate the prognosis of patients with HFNEF, to comprehensively evaluate the prognosis of HFNEF patients. Peak V02, the main efficacy indicator, is an important indicator to evaluate the aerobic work ability of the human body. Not only can it be used to evaluate the severity of HFNEF and the effect of cardiac rehabilitation training,

but also closely related to the long-term prognosis of patients. ${ }^{36-38}$ Peak oxygen consumption is also an effective and practical evaluation index of aerobic capacity and has good retest reliability. ${ }^{39}$ The anoxia threshold, a secondary therapeutic index, can reflect the body's potential to tolerate load. It is usually measured by sub-maximum exercise and is rarely affected by subjective and objective factors. It can sensitively show the balance of tissue oxygen supply and demand and accurately evaluate the anoxia metabolic capacity and cardiopulmonary function during exercise. ${ }^{40}$ In addition, Nedeljkovic ${ }^{41}$ observed that, in HFNEF patients undergoing cardiopulmonary exercise test combined with exercise load ultrasound, the equivalent slope of carbon dioxide ventilation (VE/VCO2 slope) was an independent predictor of HFNEF prognosis. At the same time, the echocardiographic index E/e' was used to evaluate cardiac diastolic function, left atrial pressure, and left ventricular filling pressure volume curves, which were estimated by this method to be very close to those of the invasive catheterization method; and it is not affected by ejection fraction and cardiac arrhythmias and has now been designated as one of the main ultrasonic screening parameters of HFNEF by the guidelines. ${ }^{42}$

In addition, during the follow-up period of 3 months, patients' clinical conditions, especially regarding the rehospitalization rate and the outpatient and inpatient costs will be tracked to comprehensively evaluate the patients'

Page $12 / 18$ 
exercise capacity and quality of life. At present, it is unclear whether the exercise capacity can be maintained after the long-term use of Yangyin Shuxin Decoction. Even so, this study will provide valid data for TCM to improve the exercise capacity of patients with HFNEF. Although it cannot fully explain the multi-linked interventional and pharmacological mechanism of TCM decoction on HFNEF, we can still use it as an intervention method and explore the mechanism from the perspective of pathophysiology in the future, because the fact that it can improve exercise tolerance in patients with HFNEF has been proven.

In conclusion, this is a single-center parallel randomized controlled trial. We will evaluate whether Yangyin Shuxin Decoction can improve the exercise capacity and quality of life of patients with HFNEF. This will provide an objective evidence for the therapeutic effect of TCM on HFNEF.

\section{Trial Status}

This trial is currently recruiting participants (protocol version 1.1, 10 November 2017). The study will run from 1 December 2017 to 30 June 2021.

\section{List Of Abbreviations}

HFNEF: Heart failure with normal ejection fraction

Peak V02: The peak oxygen consumption

CPET: Cardiopulmonary exercise test

E/e': the ratio of mitral peak velocity of early filling to early diastolic mitral annular velocity

LAVI: Left atrial volume index

LVMI: Left ventricular mass index

TR: The peak velocity of tricuspid regurgitation

BNP: B-type natriuretic peptide

NYHA: New York Heart Association

ACEl: Angiotensin-converting enzyme inhibitors

ARB: Angiotensin II Receptor Blockers

TCM: Traditional Chinese medicine

LVEF: Left ventricular ejection fraction

EQ-5D-5C: EuroQol-5 Dimension- 5 Level

BUA: Blood uric acid

UAlb: Urine microalbumin

CR: Creatinine 
BUN: Blood urea nitrogen

ALT: Alanine transaminase

CRF: Case report form

ESC: European Society of Cardiology

CPK: Creatine phosphokinase

LDH: Lactate dehydrogenase

PP: Polygonatum polysaccharide

EE: Ethanol extract

SOD: Superoxide dismutase

MDA: Malondialdehyde

AMP: Adenosine monophosphate

$\mathrm{K}^{+}$: Calcium ion

P13K: Phosphatidylinositol 3-kinase

\section{Declarations}

Acknowledgement: We thank all the participants in our study.

We would like to thank Editage (www.editage.cn) for English language editing.

\section{Authors' contributions}

JM made substantial contributions to the concept and design of the clinical trial. ZZand XW were responsible for the design, implementation, and management of the study and manuscript writing, and contributed equally to the article. SW is responsible for specimen preservation, inspection, and determination. RZ is in charge of ultrasonic testing. YL is responsible for the operation of the cardiopulmonary exercise test. QS was responsible for patient inclusion. SL and TC participated in the research scheme formulation and thesis writing. QL and HL participated in the manuscript writing, case inclusion, and patient follow-up.

Funding: This study was supported by grants from Najor Science and Technology Project of Tianjin (No. 16zxmjsy00050). The funder has not taken part in the study design, data collection and analysis, the decision to publish, or the preparation of the manuscript.

Availability of data and materials: The datasets generated and analysed during the current study will be available from the corresponding author or chief investigator on reasonable request.

Ethics approval and consent to participate: The study will be conducted according to the principles of the Helsinki Declaration. The Research Ethics Committee of the First Teaching Hospital of Tianjin University of Traditional Chinese Medicine have approved the study. If there is any modification of the protocol and informed consent, or changes of the 
principal investigator during the study, it will be submitted to the ethics committee for re-reviewing. All participants will be informed about the details of the trial, including the purpose, arrangement, probable risks and benefits. And signed informed consent will be obtained from all participants before enrolment.

Consent for publication: Not applicable.

Competing interests: The authors declare that they have no competing interests.

\section{Author details}

Affiliations: The First Teaching Hospital of Tianjin University of Traditional Chinese Medicine, 88 Changling Road, Xiqing District, Tianjin, China

\section{Authors' information}

The First Teaching Hospital of Tianjin University of Traditional Chinese Medicine, Tianjin, 300381, China.

E-mail: Zhiqiang Zhao: 13512279828@126.com; Xianliang Wang: 13920007825@126.com; Shuai Wang: wangshuai.hhht@163.com; Ruijuan Zhou: zhouruijuan-120@163.com; Quan Su: suquan1982916@163.com; Yu Liu: liuyutcm@163.com; Tao Cheng: Ctgkw1127@163.com; Qing Li: here0825@icloud.com; Shanshan Lin: 15902270931@163.com; Hua Liu: m15620628034@163.com; Jingyuan Mao: jymao@126.com.

\section{Corresponding author}

Correspondence to Jingyuan Mao.

Open Access: This is an open access article distributed under the Creative Commons Attribution License 4.0 (CCBY), which permits unrestricted use, distribution, and reproduction in any medium, provided that the original work is properly cited.

\section{References}

1. Chinese Medical Association Cardiovascular Disease Branch, Editorial Board of Chinese Journal of Cardiovascular Diseases. Chinese Heart Failure Diagnosis and Treatment Guide 2014. Chinese Journal of Cardiology. 2014;42:98122.

2. Bhatia RS, Tu JV, Lee DS, et al. Outcome of heart failure with preserved ejection fraction in a population-based study. N Engl J Med. 2006;355:260-9; doi: 10.1056/NEJMoa051530.

3. Bursi F, Weston SA, Redfield MM, et al. Systolic and diastolic heart failure in the community. JAMA. 2006;296:2209-16; doi: 10.1001/jama.296.18.2209.

4. Owan TE, Hodge DO, Herges RM, et al. Trends in prevalence and outcome of heart failure with preserved ejection fraction. N Engl J Med. 2006;355:251-9; doi: 10.1056/NEJMoa052256.

5. Zile MR, Gaesch WH, Anand IS, et al. Mode of death in patients with heart failure and a preserved ejection fraction: results from the irbesartan in heart failure with preserved ejection fraction study (I-Preserve) trial. Circulation. 2010;121:1393-405; doi: 10.1161/CIRCULATIONAHA.109.909614.

6. Huang D, Cheng JW. Pharmacologic management of heart failure with preserved ejection fraction. Ann Pharmacother. 2010;44:1933-45; doi: 10.1345/aph.1P372.

7. Yamamoto K, Otigasa $\mathrm{H}$, Hori M. Effects of carvedilo on heart failure with preserved ejection fraction; the Japanese diastolic heart failure study (J-DHF). Eur J Heart Fail. 2013;15:110-8; doi: 10.1093/eurjhf/hfs141. 
8. Sujit, Rajagopalan, Anjuman, et al. Pharmacotherapy of heart failure with normal ejection fraction (HFNEF): a systematic review. Br J Clin Pharmacol. 2011;72:369-80; doi: 10.1111/j.1365-2125.2011.03998.x.

9. Huang F-X, Xu Y, Ye Y, et al. Clinical observation on Jianxin granules for treatment of heart failure with normal LVEF. Chinese Journal of Integrative Medicine on Cardio-/Cerebrovascular Disease. 2012;10:1155-7.

10. Liu Q, Xu Z, Mao W. Therapeutic effects of Yixinshu capsule on heart function and inflammatory factors in patients with atrial fibrillation and diastolic heart failure. Chinese Journal of New Drugs and Clinical Remedies. 2011;30:766-70.

11. Zhou P, Lu J-J, Xia Y, et al. Systematic review on randomized controlled trials of oral traditional Chinese medicine in the treatment of diastolic heart failure. China Medical Herald. 2015;12:67 71.

12. Zhang Y-L, Zhu X-M. Clinical observation on Yixinshu Capsule for treatment of diastolic heart failure. Chinese Journal of Integrative Medicine on Cardio-/Cerebrovascular Disease. 2011;9:287-9.

13. Ping W, Zhao Z-Q, Hou X-Y, et al. Traditional Chinese Medicine in the Treatment of Heart Failure with Normal Ejection Fraction: A Systematic Review. Chinese Journal of Integrative Medicine on Cardio-/Cerebrovascular Disease. 2016;14:2465-71.

14. Tang Q-M, Zhao Z-Q, Wang X-L, et al. Syndrome differentiation and treatment of heart failure with normal ejection fraction. Journal of Traditional Chinese Medicine. 2017,58:1241-3.

15. Zhao Z-Q, Wang X-L, Zhang P, et al. Effects of Yangyin Shuxin Decoction on the Quality of Life in Patients with Heart Failure of Normal Ejection Fraction. Journal of Traditional Chinese Medicine. 2018;59:1843-7.

16. Chinese Medical Association Cardiovascular Disease Branch. Chinese Heart Failure Diagnosis and Treatment Guide 2014. Chinese Journal of Cardiology. 2014;42:3-10.

17. Ponikowski P, Voors A A, Anker S D, et al. 2016 ESC Guidelines for the diagnosis and treatment of acute and chronic heart failure. Rev Esp Cardiol (Engl Ed). 2016;69:1167; doi: 10.1016/j.rec.2016.11.005.

18. Fang W-J, Feng J-F, Lu X-M, et al. Effect of Cornus officinalis fruit core extract on the cardiac hypertrophy induced by two kidney two clip. Journal of Chinese medicinal materials. 2012;35:1985-9.

19. Yang M-M, Yuan X-X, Zhao G-Q, et al. Advances in studies on chemical constituents and pharmacological effects of hawthorn. Journal of Chengde Medical College. 2016;33:398-400.

20. Peng W, Ma X, Wang J, et al. Research progress on chemical constituents and pharmacological effects of Ophiopogon japonicas. Chinese Traditional and Herbal Drugs. 2018;49:477-488.

21. Chen P, Xu D-M, Lei J. Research status of chemical composition and pharmacological action of ophiopogon japonicus. Journal of Changchun College of Traditional Chinese Medicine. 2004;20:35-6.

22. Zhao W-L, Zhao Y, Tseng Y. Research progress on pharmacological effects of Polygonati Rhizoma. Chinese Traditional and Herbal Drugs. 2018;49:4439-45.

23. Lau C-W, Yao X-Q, Chen Z-Y, et al. Cardiovascular actions of berberine. Cardiovasc Drug Rev. 2001;19:234-44.

24. Chen K, Li G, Geng F, et al. Berberine reduces ischemia/reperfusion-induced myocardial apoptosis via activating AMPK and PI3K-Akt signaling in diabetic rats. Apoptosis. 2014;19:946-57; doi: 10.1007/s10495-014-0977-0.

25. Li B, Guo L-C. A Survey of the Chemical Constituents and Pharmacological Effects of Armor. Informationon Traditional Chinese Medicine. 2009;26:25-7.

26. Gao S, Liu Z, Li H, et al. Cardiovascular actions and therapeutic potential of tanshinone IIA. Atherosclerosis. 2012;220:3-10; doi: 10.1016/j.atherosclerosis.2011.06.041.

27. Tan X, Li J, Wang X, et al. Tanshinone IIA protects against cardiac hypertrophy via inhibiting calcineurin/NFATc3 pathway. Int J Biol Sci. 2011;7:383-9; doi: 10.7150/ijbs.7.383. 
28. Du H, Sun J-M, Guo X-Q, et al. The chemical composition and pharmacological action of earthworms. Jilin Journal of Traditional Chinese Medicine. 2014;34:707-9.

29. Liu Y-H, Guo J-H, Liu W-T, et al. Research progress on alkaloids from Pinellia ternata. Journal of Northwest AIF University(Nat. Sci. Ed.). 2015;43:171-7.

30. Liu Y-P, Xing S-F. Research on pharmacological action of pinellia ternate. Public Medical Forum Magazine. 2014;18:4446-7.

31. Zhang M-F, Shen Y-Q. Research Progress in Pharmacologic Effects of Pinelliae Rhizoma and Its Processed Products in Nervous and Circulatory Systems. Anti Infect Pharm. 2017;14:1643-8.

32. Yang L, Yang L. Pharmacological effect and mechanism of Trichosanthes peel on coronary heart disease. Journal of Clinical Medical. 2016;3:7495-6.

33. 3 Tan H. Study on chemical constituents and pharmacological effects of fructus aurantia. Guide of China Medicine. 2017;15:14-5.

34. Kosmala W, Holland D J, Rojek A, et al. Effect of I f-Channel Inhibition on Hemodynamic Status and Exercise Tolerance in Heart Failure With Preserved Ejection Fraction : A Randomized Trial. Journal of the American College of Cardiology. 2013; 62:1330-8; doi: 10.1016/j.jacc.2013.06.043.

35. Wan X, Li Z-H, Li J-P. Estimation of sample size in clinical studies: (1) clinical trials. Journal of Trad itional Chinese Medicine. 2007;48:504-7.

36. Lavie C J, Milani R V, Megra MR. Peak exercise oxygen pulse and prognoslsin chronic heart failure. Am J Cardiol. 2004;93:589-93; doi: 10.1016/j.amjcard.2003.11.023.

37. Oneill J O, Young J B, Poyhier C E, et al. Peak oxygen consumption as a predictior of death in patients with heart failure receiving beta blockers. Circulation. 2005;111:2313-8; doi: 10.1161/01.CIR.0000164270.72123.18.

38. Roditis P, Dimopoul OS S, Sa KD, et al. The effect of exercise training on the kinetics of oxygen uptake in patients with chronic heart failure. Eur J Cardiovasc Prew Rehabil. 2007;14:304-11.

39. Zhang J-G, Shi Q-R, Zhang X-Q. VO 2 peak: Interpretation and application. China Sport Science. 2007;27:80-5.

40. Tomono J, Adachi H, Oshima S, et al. Usefulness of anaerobic threshold to peak oxygen uptake ratio to determine the severity and pathophysiological condition of chronic heart failure. J Cardiol. 2016;68:373-8;doi:

10.1016/j.jjcc.2016.01.002.

\section{Figures}




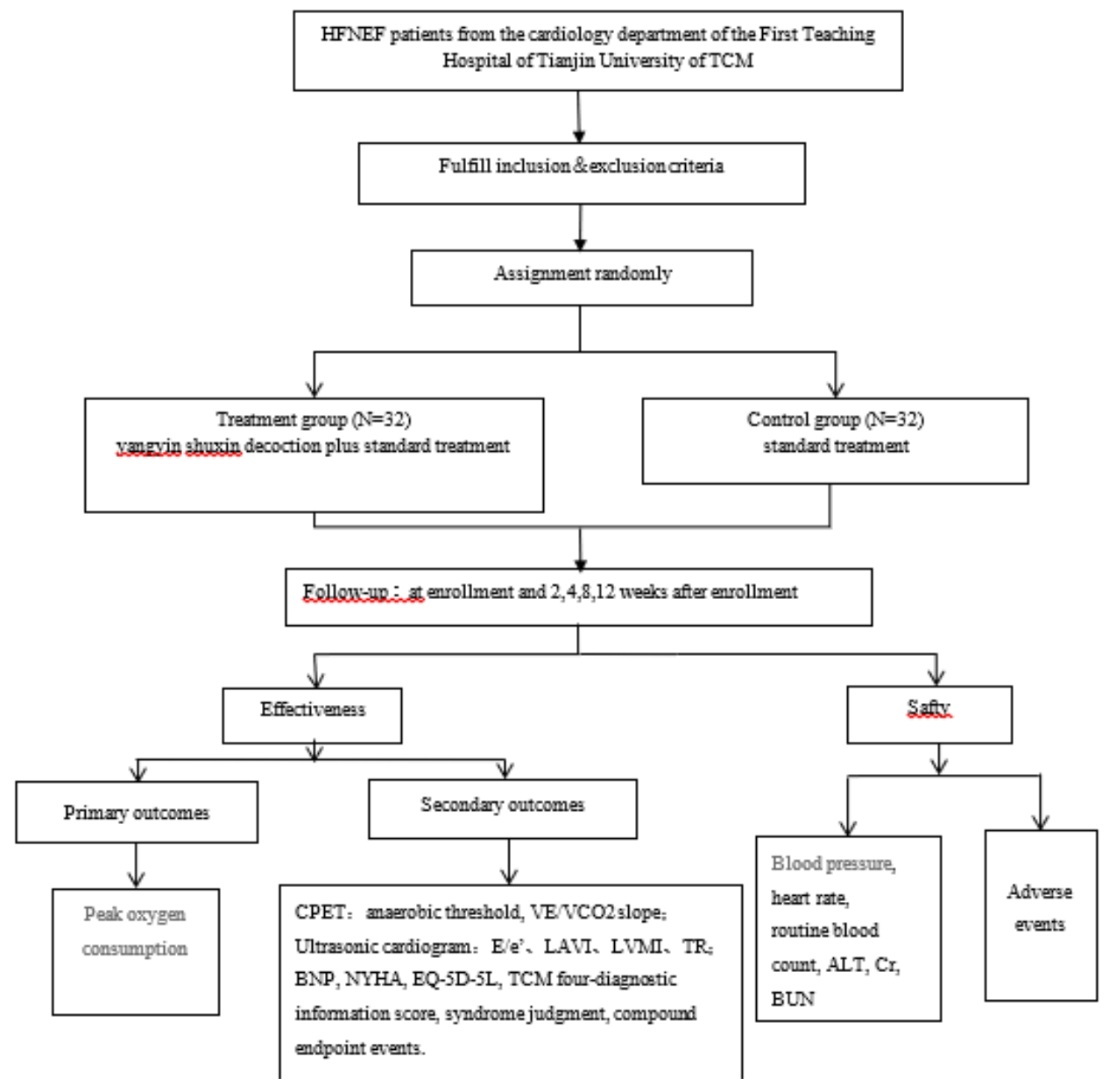

Figure 1

Study flow chart. Note: CPET: cardiopulmonary exercise test; VE/VCO2: ventilatory equivalent for carbon dioxide; EQ-

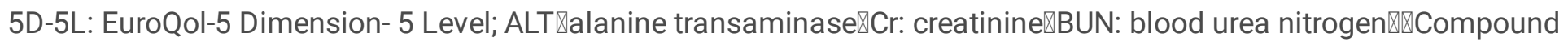
endpoint events: all-cause death, emergency/re-hospitalization for heart failure, acute coronary syndrome, revascularization, malignant arrhythmias, cardiogenic shock, stroke, pulmonary embolism, and so on.

\section{Supplementary Files}

This is a list of supplementary files associated with this preprint. Click to download.

- Formula.docx

- Additionalfile1.doc

- SPIRITfigure.pdf 